\title{
Comparison of risk stratification models for pregnancy in congenital heart disease
}

\author{
Nathalie Denayer ${ }^{\mathrm{a}}$, Els Troost ${ }^{\mathrm{b}}$, Béatrice Santens ${ }^{\mathrm{b}}$, Pieter De Meester ${ }^{\mathrm{b}, \mathrm{c}}$, Leen Roggen ${ }^{\mathrm{b}}$, Philip Moons ${ }^{\mathrm{d}, \mathrm{e}, \mathrm{f}}$, \\ Kristel Van Calsteren ${ }^{\mathrm{g}}$, Werner Budts ${ }^{\mathrm{b}, \mathrm{c}}$, Alexander Van De Bruaene ${ }^{\mathrm{b}, \mathrm{c}, *}$ \\ a Faculty of Medicine, Department of Internal Medicine, KU Leuven, Belgium \\ ${ }^{\mathrm{b}}$ Division of Structural and Congenital Cardiology, University Hospitals Leuven, Belgium \\ c Department of Cardiovascular Sciences, KU Leuven, Belgium \\ d Department of Public Health and Primary Care, KU Leuven, Belgium \\ e Institute of Health and Care Science, University of Gothenburg, Sweden \\ ${ }^{\mathrm{f}}$ Department of Paediatrics and Child Health, University of Cape Town, South Africa \\ ${ }^{g}$ Department of Obstetrics and Gynecology, University Hospitals Leuven, Belgium.
}

\section{A R T I C L E I N F O}

\section{Article history:}

Received 1 July 2020

Received in revised form 7 September 2020

Accepted 10 September 2020

Available online $\mathrm{xxxx}$

\section{Keywords:}

Pregnancy

Congenital heart disease

Risk stratification

\begin{abstract}
A B S T R A C T
Background: Pregnancy in women with congenital heart disease (CHD) is associated with increased risk for maternal cardiac complications. Several risk stratification models are used to predict adverse cardiac outcome in women with CHD who become pregnant. This study was set up as an exploratory study to provide a head-tohead comparison of the 4 most commonly used models: CARPREG, CARPREG II and ZAHARA risk scores and mWHO risk classification.

Methods and results: We randomly selected 100 women from the database of paediatric and congenital heart disease of the University Hospitals Leuven. Individual pregnancy risk scores were retrospectively calculated and summarized in a weighted average risk for each risk stratification model. To evaluate accuracy of each model, the weighted average risk was plotted against the actual observed number of "cardiac events" as defined in the respective risk models. Maternal adverse cardiac events occurred in $8 \%$ of our study population. Weighted average risks were plotted versus the observed number of events for each model: $10.1 \%$ versus $4.0 \%$ for CARPREG, 8.6\% versus $5.0 \%$ for CARPREG II, $11.1 \%$ versus $8.0 \%$ for ZAHARA and $12.4 \%$ versus $8.0 \%$ for the mWHO classification.

Conclusion: All risk models overestimated maternal cardiac risk. The ZAHARA risk model appeared to be a closer reflection of maternal risk in our cohort of CHD patients. More research on a larger study population is needed.
\end{abstract} (c) 2020 Elsevier B.V. All rights reserved.

\section{Background}

Due to advances in cardiac surgery, paediatric cardiology and intensive care, long-term outcome of congenital heart disease (CHD) has substantially improved [1]. As a consequence, most patients with $\mathrm{CHD}$ reach childbearing age, with growing numbers of CHD patients going through pregnancy [2-4]. Nevertheless, pregnancy in women with CHD is associated with increased risk for maternal cardiac and obstetric as well as fetal and neonatal complications [5,6]. Accurate risk estimation for counselling before pregnancy is therefore of utmost importance.

Several risk models have been proposed to predict outcomes in pregnant CHD patients. The four most commonly used models are the

* Corresponding author at: Structural and Congenital Cardiology, University Hospitals Leuven, Herestraat 49, 3000 Leuven, Belgium.

E-mail address: alexander.vandebruaene@uzleuven.be (A. Van De Bruaene).
CARPREG (CARdiac disease in PREGnancy) [7], CARPREG II ${ }^{8}$, ZAHARA (Zwangerschap bij Aangeboren HARtAfwijkingen; translated as 'Pregnancy and Congenital Heart Disease') [9] and the modified World Health Organization (mWHO) [10] risk stratification models.

The recent European Society of Cardiology (ESC) pregnancy guidelines for patients with cardiovascular disease suggest a preferential use of the mWHO risk stratification [5]. However, an evaluation of the different risk models and a head-to-head comparison in CHD patients who are thoroughly phenotyped, has not yet been performed. It is currently unclear whether a head-to-head comparison is possible since variables used for risk stratification differ across all four risk models and the outcomes (maternal, foetal, and obstetric) are defined differently. Moreover, there are currently few data available that provide an estimate of each models' performance in a contemporary high-risk pregnancy clinic. Therefore, this exploratory study aimed evaluating the feasibility of identifying the risk model that most accurately predicts outcome. 
Table 1

Baseline characteristics.

\begin{tabular}{|c|c|}
\hline & $\mathrm{N}$ \\
\hline \multicolumn{2}{|l|}{ Parity } \\
\hline 0 & 52 \\
\hline 1 & 38 \\
\hline 2 & 7 \\
\hline 3 & 3 \\
\hline \multicolumn{2}{|l|}{ Type of CHD } \\
\hline \multicolumn{2}{|l|}{ Shunt lesion } \\
\hline Atrial septal defect & 14 \\
\hline Ventricular septal defect & 34 \\
\hline Atrioventricular septal defect & 8 \\
\hline Patent foramen ovale & 1 \\
\hline Patent ductus arteriosus & 8 \\
\hline \multicolumn{2}{|l|}{ Left-sided lesion } \\
\hline Mitral valve stenosis & 1 \\
\hline Mitral valve insufficiency & 1 \\
\hline Bicuspid aortic valve & 5 \\
\hline Aortic valve stenosis & 5 \\
\hline Subaortic valve stenosis & 4 \\
\hline Coarctation of the aortae & 16 \\
\hline \multicolumn{2}{|l|}{ Right-sided lesion } \\
\hline Pulmonary valve stenosis & 8 \\
\hline Subpulmonary valve stenosis & 1 \\
\hline Double outlet right ventricle & 3 \\
\hline Double chambered right ventricle & 1 \\
\hline \multicolumn{2}{|l|}{ Other } \\
\hline Tetralogy of Fallot & 15 \\
\hline Transposition of the great arteries & 6 \\
\hline Partial anomalous pulmonary drainage & 3 \\
\hline Univentricular heart & 2 \\
\hline Marfan syndrome & 2 \\
\hline Scimitar syndrome & 1 \\
\hline \multicolumn{2}{|l|}{ Circulation } \\
\hline Biventricular & 98 \\
\hline Univentricular & 2 \\
\hline Left systemic ventricle & 94 \\
\hline Right systemic ventricle & 6 \\
\hline Corrected cyanotic CHD & 26 \\
\hline Cyanosis & 0 \\
\hline Residual shunt & 11 \\
\hline Antecedent of cardiovascular event* & 15 \\
\hline \multicolumn{2}{|l|}{ NYHA-class } \\
\hline \multicolumn{2}{|l|}{ Before pregnancy } \\
\hline 1 & 97 \\
\hline 2 & 2 \\
\hline 3 & 1 \\
\hline 4 & 0 \\
\hline \multicolumn{2}{|l|}{ During pregnancy } \\
\hline 1 & 90 \\
\hline 2 & 8 \\
\hline 3 & 2 \\
\hline 4 & 0 \\
\hline After pregnancy & \\
\hline 1 & 98 \\
\hline 2 & 2 \\
\hline 3 & 0 \\
\hline 4 & 0 \\
\hline LVOT obstruction & \\
\hline LVOT obstruction with PIG $>50 \mathrm{mmHg}$ and/or AVA $<1.0 \mathrm{~cm}^{3}$ & 2 \\
\hline LVOT obstruction PIG $>30 \mathrm{mmHg}$ and/or AVA $<1.5 \mathrm{~cm}^{2}$ & 4 \\
\hline Mitral valve stenosis & 0 \\
\hline Left ventricular dysfunction & 1 \\
\hline Right ventricle outflow tract (RVOT) obstruction & 1 \\
\hline Pulmonary hypertension & 0 \\
\hline Valve insufficiency & 34 \\
\hline Aortic dilation & 5 \\
\hline Mechanical valve & 1 \\
\hline Pacemaker & 3 \\
\hline Maternal risk factors & \\
\hline Smoking & 15 \\
\hline Alcohol consumption & 0 \\
\hline Obesity & 9 \\
\hline Diabetes & 0 \\
\hline Arterial hypertension before pregnancy & 2 \\
\hline Use of cardiac medication before pregnancy & 15 \\
\hline Use of anticoagulants before pregnancy & 3 \\
\hline
\end{tabular}

Table 1 (continued)

\begin{tabular}{|c|c|}
\hline & $\mathrm{N}$ \\
\hline Age $<20$ or $>35$ years during pregnancy & 9 \\
\hline Multiple birth & 3 \\
\hline \multicolumn{2}{|l|}{ Risk scores } \\
\hline \multicolumn{2}{|l|}{ CARPREG } \\
\hline 0 & 79 \\
\hline 1 & 20 \\
\hline$>1$ & 1 \\
\hline \multicolumn{2}{|l|}{ CARPREG II } \\
\hline $0-1$ & 73 \\
\hline 2 & 10 \\
\hline 3 & 10 \\
\hline 4 & 2 \\
\hline$>4$ & 5 \\
\hline \multicolumn{2}{|l|}{ ZAHARA } \\
\hline $0-0.50$ & 47 \\
\hline $0.51-1.50$ & 35 \\
\hline $1.51-2.50$ & 10 \\
\hline $2.51-3.50$ & 1 \\
\hline$>3.51$ & 7 \\
\hline \multicolumn{2}{|l|}{ mWHO } \\
\hline I & 25 \\
\hline II & 29 \\
\hline II - III & 33 \\
\hline III & 10 \\
\hline IV & 3 \\
\hline
\end{tabular}

CHD: congenital heart disease - NYHA: New York Heart Association Class - LVOT: left ventricular outflow tract - AVA: aortic valve area - RVOT: right ventricular outflow tract.

* Cardiovascular events: transient ischemic attack (TIA), cerebrovascular accident (CVA), arrhythmia or heart failure (defined as need for medication, hospitalization or induction of labour due to maternal complications).

\section{Materials and methods}

\subsection{Patient selection}

As a first step, 100 patients with documented pregnancy were randomly selected from the database of paediatric and congenital heart disease of the University Hospitals Leuven. For the purpose of the study, only one pregnancy was included per patient. In a second step, because of missing records within these first 100 patients, 13 additional, randomly selected records were added to reach a total of 100 patients (12 patients had no data on delivery and/or postpartal period; one patient was not followed in our centre during pregnancy). Patients' records were reviewed after pseudonymizing patient data conform the Global Data Protection Regulation (GDPR). The Research Ethics Committee UZ/KU Leuven approved the study on November 28th, 2018 (reference MP007849) and the study was conducted in compliance with the principles of the Declaration of Helsinki.

\subsection{Baseline and outcome characteristics}

Baseline characteristics were retrospectively extracted from medical records obtained during an outpatient visit at the clinical department of CHD during the pre-pregnancy period. Following baseline characteristics were extracted: age, parity, type of $\mathrm{CHD}$, circulation type (biventricular, univentricular, right or left systemic ventricle, cyanotic or acyanotic), presence of a residual shunt, prior history of any of following: transient ischemic attack (TIA), cerebrovascular accident (CVA), arrhythmia or heart failure (defined as: need for medication, hospitalization), induction of labour due to maternal complications, NYHA class before, during and after pregnancy and maternal cyanosis (defined as oxygen saturation $<90 \%$ ). Echocardiographic data from the pre-pregnancy period included left ventricular outflow tract obstruction (divided in 2 gradations: (a) peak instantaneous gradient (PIG) $>50 \mathrm{mmHg}$ and/or aortic valve area (AVA) $<1.0 \mathrm{~cm}^{2}$; (b) PIG $>30 \mathrm{mmHg}$ and/or AVA $<1.5 \mathrm{~cm}^{2}$ ), mitral valve stenosis (defined as mitral valve area (MVA) $<2.0 \mathrm{~cm}^{2}$ ), left ventricular dysfunction (defined as ejection fraction $<40 \%$ ), right ventricle outflow tract (RVOT) obstruction (defined as 
RVOT gradient $>50 \mathrm{mmHg}$ ), pulmonary hypertension (defined as right ventricular systolic pressure $>50 \mathrm{mmHg}$ ), valve insufficiency (defined as $\geq$ moderate pulmonary, subpulmonary atrioventricular, aortic or systemic atrioventricular regurgitation), aortic dilation (defined as dilation $>40 \mathrm{~mm}$ ). The presence of a mechanical valve or pacemaker was recorded. Finally, the following additional maternal risk factors were listed: smoking, alcohol consumption, obesity (defined as body mass index $>30 \mathrm{~kg} / \mathrm{m}^{2}$ ), diabetes, arterial hypertension before pregnancy, the use of cardiac medication or anticoagulants before pregnancy, age $<20$ or $>35$ years during pregnancy and multiple births.

For maternal, obstetric and neonatal outcomes, medical records of the follow-up visits during pregnancy and postpartum period (up to 1 year postpartum) were reviewed. Following maternal outcomes (during pregnancy or in the postpartal period) were recorded: transient ischemic attack (TIA), cerebrovascular accident (CVA), arrhythmia or heart failure (defined as the need for medical therapy, hospitalization or induction of labour), venous thromboembolic complications, coronary ischemia and mortality. Obstetric outcomes were defined as: arterial hypertension during pregnancy, pre-eclampsia, HELLP syndrome (Haemolysis, Elevated Liver enzymes and a Low Platelet count), type of delivery (vaginal, primary or secondary Caesarean section) and postpartum bleeding (defined as $>500 \mathrm{ml}$ blood loss in case of vaginal delivery or $>1000 \mathrm{ml}$ blood loss in case of Caesarean section). Neonatal outcomes included prematurity (defined as birth $<37$ weeks of gestation), severe prematurity (defined as birth $<33$ weeks of gestation), low birth weight (defined as weight $<10$ th percentile) and mortality (defined as intra-uterine death $>20$ weeks of gestation or death before the age of 1 year).

\subsection{Risk score calculation}

Based on the maternal baseline characteristics, individual pregnancy risk scores according to the 4 risk models (CARPREG, CARPREG II, ZAHARA, and $\mathrm{mWHO}$ ) were calculated and summarized in a global risk score for the whole study population (see section Statistical analysis). Summary tables of the risk models, including predictors of risk, estimated risk for maternal cardiac events and definition of maternal cardiac events are included in the Appendix (Table 1-4).

\subsection{Statistical methods}

Data were analysed using SPSS $₫$ for Mac (version 23, SPSS, Chicago) and tested for normality with the Kolmogorov-Smirnov test. Descriptive data for continuous variables are presented as means \pm SD or as medians with interquartile ranges (IQR) as appropriate. Descriptive data for discrete variables are presented as frequencies, which corresponds with the percentages, since the size for this feasibility study was set at $100 \mathrm{pa}-$ tients. For each patient the individual maternal risk score for all 4 models was calculated. For each model we calculated predicted risk of adverse maternal cardiac events (for each score within the risk model as well as a composite risk per risk model). For each model, we calculated a receiver-operating curve. The composite risk per model was calculated as follows: (1) When the predicted risk (corresponding to a risk score) was expressed as a range, the mean value of this range was used and (2) the composite predicted risk was obtained by multiplying the number of patients per risk score category with the corresponding (mean) predicted risk, followed by summation of results giving a weighted average risk and (3) calculating the ratio of observed risk over weighted average risk (closer to 1 indicating better predictive accuracy). All tests were two-sided and $P<0.05$ was considered statistically significant.

\section{Results}

\subsection{Maternal baseline characteristics}

One hundred women with CHD were included in the study. All baseline population characteristics are summarized in Table 1. Mean maternal age was $30.4 \pm 3.7$ years. The four most common CHDs in our population were ventricular septal defect (34\%), coarctation of the aortae (16\%), tetralogy of Fallot (15\%) and atrial septal defect (14\%). The majority of the study population (74\%) had acyanotic CHD. There were no patients who had pre-pregnancy cyanosis (defined as resting oxygen saturation $<90 \%$ ) and only one patient was identified with pulmonary hypertension. In $15 \%$ of the patients, there was a history of maternal events prior to pregnancy. Echocardiographic parameters prior to pregnancy and required for risk calculation are also listed in Table 1. The most commonly observed hemodynamic lesion was valve insufficiency, present in $34 \%$ of the patients.

\subsection{Calculated risk scores}

CARPREG, CARPREG II and ZAHARA risk scores and mWHO risk classification were retrospectively applied. We grouped risk scores as described in the original study articles [7-10]. Fig. 1 summarizes the number of patients per score for each model, the predicted risk of adverse maternal cardiac events per score for each model and the ROC area under the curve for each model.

\subsection{Maternal, obstetric and neonatal outcomes}

The observed rate of maternal cardiac complications in our study population was $8 \%$ (Table $2 \mathrm{a}$ and Table $2 \mathrm{~b}$ :). Clinical signs of heart failure were present in 4 patients. Three patients developed arrhythmia: two patients showed runs of non-sustained ventricle tachycardia on cardiac Holter monitoring, the third patient had episodes of atrial fibrillation. One patient died on the 4 th day postpartum. This was a sudden cardiac death, without further information in the available records. Venous thrombo-embolic complication occurred in one patient, but since this was a postpartal ovarian vein thrombosis, not counted as a cardiac thromboembolic event. No cerebrovascular events or episodes of coronary ischemia were documented. Obstetric and neonatal outcomes are also summarized in Table 2. Thirteen percent of children were delivered prematurely, two of them were born before 33 weeks of gestation.

\subsection{Comparison of the risk estimation models and observed events}

As described above, a composite risk was calculated for all 4 risk score models. Weighted composite risks were $10.1 \%$ according to CARPREG, 8.6\% according to CARPREG II, $11.1 \%$ according to ZAHARA and $12.4 \%$ according to the mWHO classification. Weighted composite risk versus observed risk was $10.1 \%$ versus $4 \%$ for CARPREG, $8.64 \%$ versus $5 \%$ for CARPREG II, $11.1 \%$ versus $8 \%$ for ZAHARA and $12.4 \%$ versus $8 \%$ for the mWHO classification (Fig. 2). Predictive accuracy for each risk model is summarized in Table 3.

\section{Discussion}

The main finding of this exploratory study was that the number of the observed maternal cardiovascular events was lower than the estimated number of events by all four risk models. In general, risk stratification based on data coming from ZAHARA, CARPREG, CARPREG II and $\mathrm{mWHO}$ all seem to overestimate actual risk in pregnant patients with CHD. The ZAHARA risk model came the closest to observed risk in our CHD patient population.

Maternal adverse cardiac events occurred in $8 \%$ of our study population, which is similar to the incidence of the cardiac events reported in other studies [7-9,11-20]. There is a certain variation of event rates among different studies, ranging from 6.7 to $25 \%$, which is likely due to the heterogeneity of the study populations. Our study cohort was quite similar to the CARPREG, CARPREG II and ZAHARA cohorts in terms of maternal age (mean maternal age 30 years) and parity status (52\% nulliparous). The CARPREG I and II derivation cohorts also included non-CHD patients (26 and 36.3\%, respectively), whereas the 
CARPREG

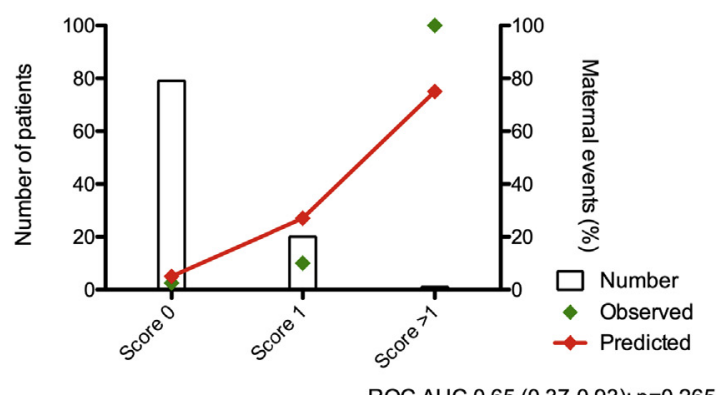

ZAHARA

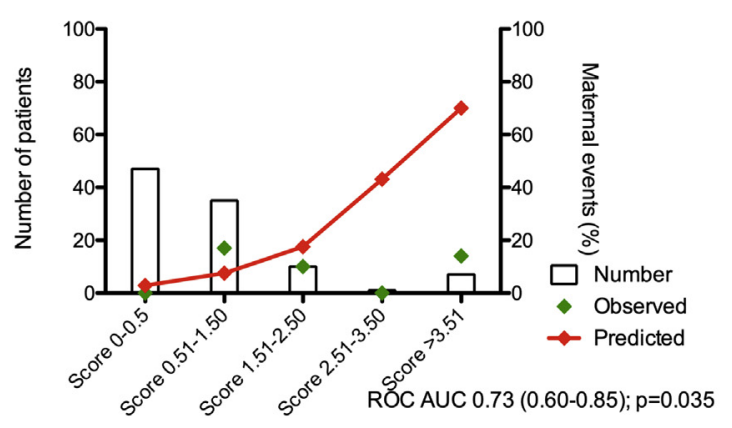

CARPREG 2

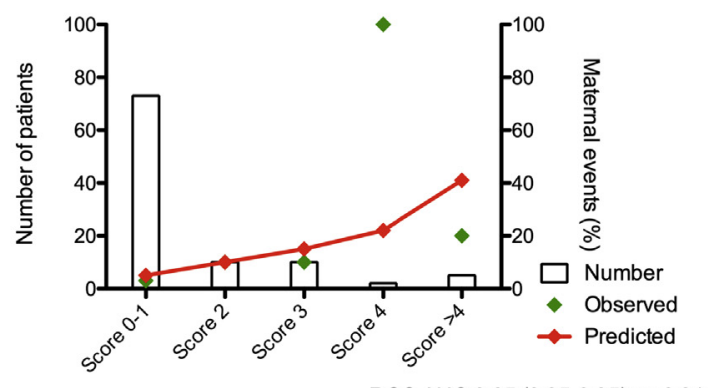

ROC AUC 0.65 (0.35-0.95); $\mathrm{p}=0.316$

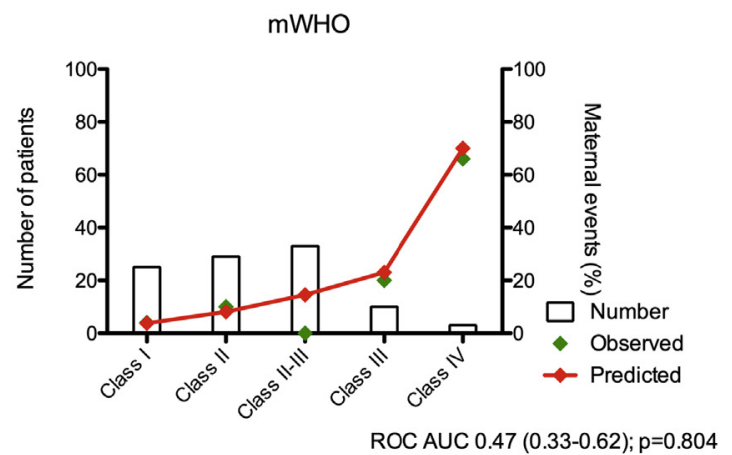

Fig. 1. Number of patients, predicted risk for adverse maternal events and receiver operating curve (ROC) area under the curve (AUC) for the different risk stratification models.

ZAHARA did not. Similarly, our study was slightly biased due to a heterogenous distribution of the underlying CHD with the majority of patients having anatomical mild to moderate disease. This selection bias is often difficult to avoid in a tertiary care setting where a pregnancy heart team is responsible for pre-pregnancy counselling of the patient. Pre-pregnancy counselling may (rightfully) discourage some patients from becoming pregnant. It is also reflected in our study with $>75 \%$ of patients in the first risk category according to CARPREG and CARPREG 2. This has implications on the clinical utility of these risk stratification tools for our patient population.

ZAHARA, CARPREG, CARPREG II, and mWHO are used in daily practice to estimate maternal cardiac risk related to pregnancy. Our intention was to compare these four risk models in a real-world setting. Moreover, this study is the first to include the CARPREG II risk stratification [8]. We calculated a weighted average risk for the study cohort based on all four risk stratification models. By comparing the weighted average risk with the observed risk, we were able to estimate the predictive accuracy of each model. Unfortunately, we were unable to perform a more detailed risk analysis because of the insufficient number of patients included in the study. An additional problem is that risk is often presented as a 'range'. We decided to use the 'mean' value to have an absolute number to work with and to allow data plotting. Although this may be criticized from a statistical point of view, it is a reflection of what is happening in daily clinical practice. The same ranges are used when discussing the potential risk with the patient during a pre-pregnancy counselling. Ranges provide only a rough estimate, and currently there are no tools to discriminate beyond the numbers of the ranges.

Overall, the weighted average risks per model were higher when compared to the observed number of events, indicating that in our patient cohort, all four risk models overestimated maternal cardiac risk. Based on the ratio of observed to estimated number of events, the ZAHARA risk model provided the most accurate risk estimate of maternal complications in our study population. Our findings differ from conclusions of other similar studies [11-14,21], but these studies did not only include CHD patients. The ESC guidelines 2018 on pregnancy indicated that the mWHO classification is considered the best model for the estimation of maternal cardiac risk [5]. Although our results (derived from a relatively small sample) appear to differ

Table 2a

Maternal, obstetric and neonatal outcomes.

\begin{tabular}{ll}
\hline Maternal outcomes & $\mathrm{N}$ \\
\hline Cardiovascular event* & 8 \\
$\quad$ Cerebrovascular event (TIA or CVA) & 0 \\
Arrhythmia & 3 \\
Heart failure & 4 \\
$\quad$ Sudden cardiac death, not otherwise specified & 1 \\
Event, as defined in the original study of the risk model & \\
$\quad$ CARPREG & 4 \\
CARPREG II & 5 \\
ZAHARA & 8 \\
mWHO & 8 \\
Venous thrombo-embolic complications & $1 * *$ \\
Coronary ischemia & 0 \\
Obstetric outcomes & $\mathrm{N}$ \\
Arterial hypertension & 6 \\
Pre-eclampsia & 5 \\
HELLP syndrome & 0 \\
Type of delivery & \\
Vaginal & \\
Primary Caesarean section & 72 \\
Secondary Caesarean section & 23 \\
Postpartum bleeding & 5 \\
Neonatal outcomes & 5 \\
Prematurity & \\
Severe prematurity & $\mathrm{N}$ \\
Low birth weight & 13 \\
Mortality & 2 \\
\hline
\end{tabular}

TIA: transient ischemic attack - CVA: cerebrovascular accident - HELLP: Haemolysis, Elevated Liver enzymes and a Low Platelet count.

* Cardiovascular events: transient ischemic attack (TIA), cerebrovascular accident (CVA), arrhythmia or heart failure (defined as need for medication, hospitalization or induction of labour due to maternal complications).

** non-cardiac thrombo-embolic event: postpartal ovarian vein thrombosis, hence not counted. 
Table 2b

Maternal events according to underlying anatomy.

\begin{tabular}{|c|c|c|c|c|}
\hline Patient & Anatomy & Age (years) & Event & Delivery \\
\hline 3 & Repaired tetralogy of Fallot & 28 & Non-sustained VT & 34 weeks, vaginal delivery \\
\hline 23 & Repaired tetralogy of Fallot & 37 & Heart failure & 37 weeks, vaginal delivery \\
\hline 59 & Marfan syndrome & 29 & Sudden cardiac death 4 days postpartum & 36 weeks, vaginal delivery \\
\hline 60 & TGA-VSD post Senning repair & 33 & Heart failure & 36 weeks, caesarean section \\
\hline 62 & Tetralogy of Fallot & 39 & Non-sustained VT & 39 weeks, vaginal delivery \\
\hline 69 & Tetralogy of Fallot & 31 & Atrial fibrillation & 38 weeks, vaginal delivery \\
\hline 70 & DILV-TGA post TCPC Fontan & 31 & Heart failure & 31 weeks, caesarean section \\
\hline 88 & TGA post Senning repair & 29 & Heart failure & 38 weeks, vaginal delivery \\
\hline
\end{tabular}

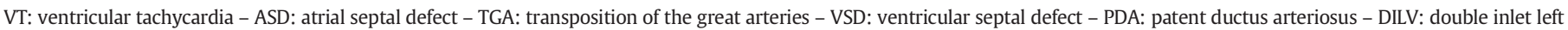
ventricle - TCPC: total cavopulmonary connection.

\section{CARPREG}

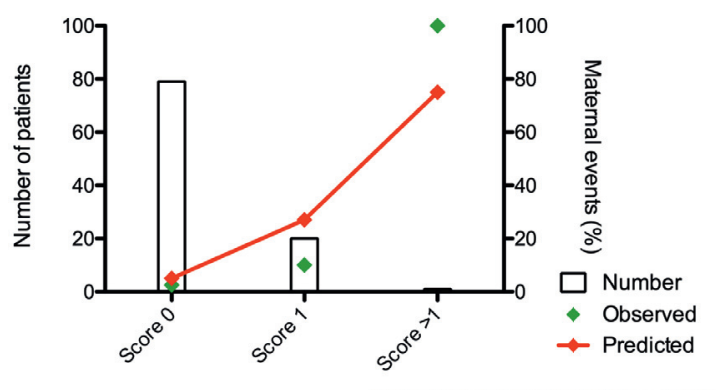

ROC AUC 0.65 (0.37-0.93); $p=0.265$

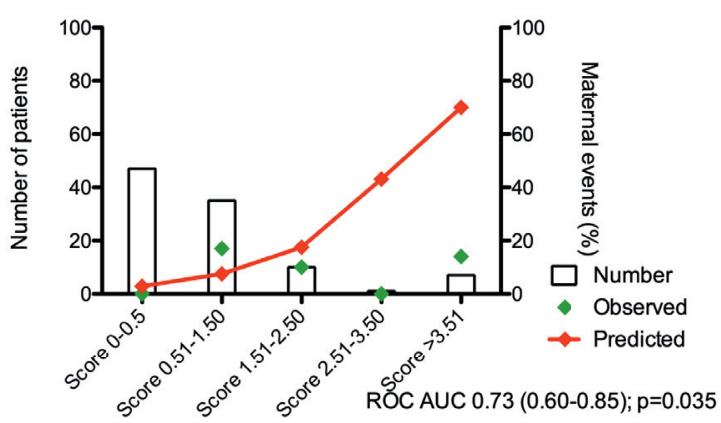

\section{CARPREG 2}

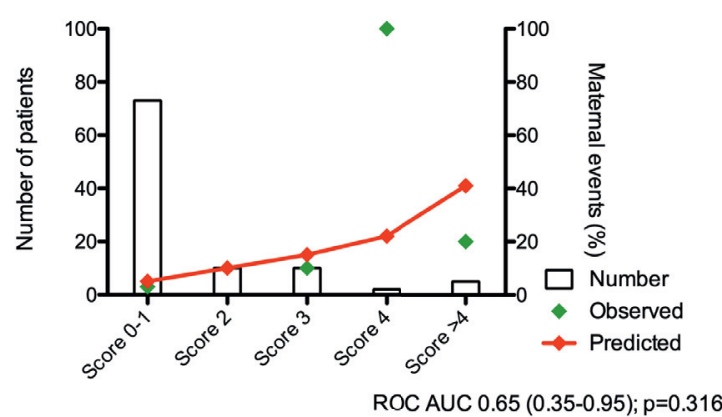

$\mathrm{mWHO}$

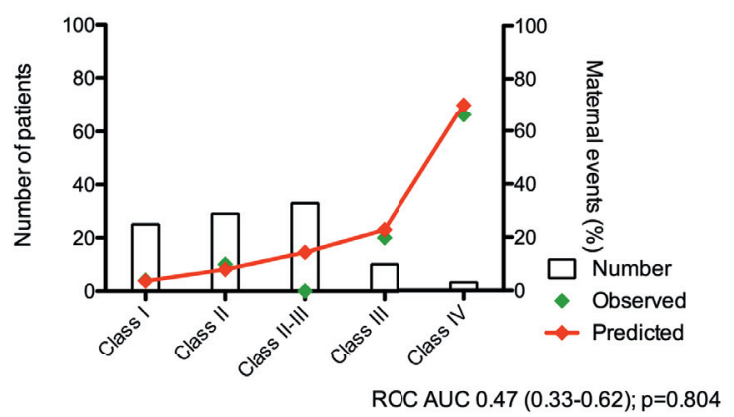

Fig. 2. Weighted average risk versus observed risk for each risk stratification model.

from these recommendations, the ESC guidelines encompass all types of heart disease, not just CHD. Moreover, they primarily aim at providing a practical guidance for follow-up. Still, investigators of the prospective Registry Of Pregnancy And Cardiac disease (ROPAC) observed a moderate performance of the $\mathrm{mWHO}$ classification in their large worldwide multicentre cohort (in which $70 \%$ of patients has CHD) [22]. In a recent study on two Chinese cohorts (with $62.5 \%$ and $70.1 \%$ CHD patients), the mWHO classification also does not appear to be superior. A new risk score model, the Renji score, was proposed and validated for risk estimation in pregnant women with heart disease in Eastern China [23]. Indeed, variability in the performance of risk models may be related to population-specific characteristics. A well-developed counselling plan for patients at high risk of adverse cardiac events during pregnancy is expected in centres with expertise in CHD. As a consequence, the low risk CHD patients were the most common ones in our study population. Only one patient

Table 3

Calculated and observed number of events according to the different risk models.

\begin{tabular}{lllr}
\hline & $\begin{array}{l}\text { Weighted average risk (\%) } \\
\text { (estimated number of events per risk model) }\end{array}$ & Observed number of events (\%) \\
\hline CARPREG & 10.1 & 4 & 0.40 \\
CARPREG II & 8.6 & 5 & 0.58 \\
ZAHARA & 11.1 & 8 & 0.72 \\
mWHO & 12.4 & 8 & 0.64 \\
\hline
\end{tabular}


had pulmonary hypertension, which is considered to be an important risk factor for adverse outcome [20,24-26]. A head-to-head comparison of the different risk models is difficult since the risk models were constructed in different patient populations with different outcome measures. The ZAHARA risk score was determined in a Dutch multicentre CHD-population. The CARPREG and CARPREG II risk scores were validated in a Canadian multicentre population that included CHD and non-CHD diagnoses (respectively $74 \%$ and $63.7 \%$ of the study cohort with CHD). The mWHO classification was designed for an even broader population with more diverse cardiovascular diseases. Therefore, taking these arguments into consideration, it is not surprising that the ZAHARA risk model fitted best with our study population of CHD patients.

As a consequence, we are still aiming for a more accurate maternal risk modelling. Increasing the number of patients will not only lower the heterogeneity of studied cohort, it will also be important to get a mix of patients from developed countries with good accessibility to health care and patients from developing countries, from which we might expect more pregnancies in high risk patients $[17,20]$. If the findings in this exploratory study are confirmed - the fact that there is a difference between observed and predicted maternal risk - new and better models are required. In addition, accurate predication of obstetric and neonatal complications appears difficult to achieve.

\section{Limitations}

The retrospective nature of this study is a first limitation. Second, study subjects were randomly selected. However, selection bias may be present as all patients were selected from one centre (UZ Leuven). Moreover, UZ Leuven is a tertiary care university hospital. Therefore, the selected patients may not represent a general population. There may be a trend of referral of the more complicated cases. On the other hand, the existing risk estimation models might be applied to our study population, resulting in negative counselling of woman at high risk of cardiac events. Third, the relative low number of patients limits the generalizability of our findings. However, this pilot study tends to evaluate a method for comparison, rather than formulate conclusions about the risk models themselves.

\section{Conclusion}

In this retrospective cohort study, we evaluated whether it is feasible to identify the most accurate risk model to predict maternal cardiac outcome. All risk models overestimated the observed maternal risk. The ZAHARA risk stratification (derived from patients with CHD) came the closest to the observed risk in our cohort of pregnant CHD patients. More research on a larger study population is needed.

\section{Funding}

None.

\section{Grant support}

None

Declaration of Competing Interest

The authors report no relationship that could be construed as a conflict of interest.

\section{Appendix A. Supplementary data}

Supplementary data to this article can be found online at https://doi. org/10.1016/j.ijcard.2020.09.033.

\section{References}

[1] P. Moons, L. Bovijn, W. Budts, A. Belmans, M. Gewillig, Temporal trends in survival to adulthood among patients born with congenital heart disease from 1970 to 1992 in Belgium, Circulation. 122 (2010) 2264-2272.

[2] W. Drenthen, P.G. Pieper, J.W. Roos-Hesselink, W. van Lottum, A.A. Voors, B. Mulder, A. van Dijk, H. Vliegen, S.C. Yap, P. Moons, T. Ebels, D. van Veldhuisen, Outcome of pregnancy in women with congenital heart disease - a literature review, J. Am. Coll. Cardiol. 49 (2007) 2303-2311.

[3] Opotowsky AR, Siddiqi OK and Webb GD. Trends in Hospitalizations for Adults With Congenital Heart Disease in the U.S. Journal of the American College of Cardiology. 2009;54:460-467.

[4] P. Khairy, R. Ionescu-Ittu, A.S. Mackie, M. Abrahamowicz, L. Pilote, A.J. Marelli, Changing mortality in congenital heart disease, J. Am. Coll. Cardiol. 56 (2010) 1149-1157.

[5] V. Regitz-Zagrosek, J.W. Roos-Hesselink, J. Bauersachs, C. Blomström-Lundqvist, R. Cífková, M. De Bonis, B. Iung, M.R. Johnson, U. Kintscher, P. Kranke, I.M. Lang, J. Morais, P.G. Pieper, P. Presbitero, S. Price, G.M.C. Rosano, U. Seeland, T. Simoncini, L. Swan, C.A. Warnes, 2018 ESC guidelines for the management of cardiovascular diseases during pregnancy, Eur. Heart J. 39 (2018) 3165-3241.

[6] S.C. Siu, J.M. Colman, S. Sorensen, J.F. Smallhorn, D. Farine, K.S. Amankwah, J.C. Spears, M. Sermer, Adverse neonatal and cardiac outcomes are more common in pregnant women with cardiac disease, Circulation. 105 (2002) 2179-2184.

[7] C.S. Siu, M.M. Sermer, N.J. Colman, C.A. Alvarez, M.L.-A. Mercier, L.B. Morton, C.C. Kells, A.M. Bergin, P.M. Kiess, C.F. Marcotte, W.D. Taylor, S.E. Gordon, F.J. Spears, F.J. Tam, F.K. Amankwah, F.J. Smallhorn, F.D. Farine, F.S. Sorensen, Prospective multicenter study of pregnancy outcomes in women with heart disease, Circulation: Journal of the American Heart Association. 104 (2001) 515-521.

[8] C. Silversides, J. Grewal, J. Mason, M. Sermer, M. Kiess, V. Rychel, R. Wald, J. Colman, S. Siu, Pregnancy outcomes in women with heart disease, J. Am. Coll. Cardiol. 71 (2018) 2419-2430.

[9] W. Drenthen, E. Boersma, A. Balci, P. Moons, J.W. Roos-Hesselink, B.J.M. Mulder H.W. Vliegen, A.P.J. van Dijk, A.A. Voors, S.C. Yap, D.J. van Veldhuisen, P.G. Pieper, Predictors of pregnancy complications in women with congenital heart disease, Eur. Heart J. 31 (2010) 2124-2132.

[10] S. Thorne, A. Macgregor, C. Nelson-Piercy, Risks of contraception and pregnancy in heart disease, Heart. 92 (2006) 1520.

[11] A. Pijuan-Domènech, L. Galian, M. Goya, M. Casellas, C. Merced, I. Ferreira-Gonzalez, J.R. Marsal-Mora, L. Dos-Subirà, M.T. Subirana-Domènech, V. Pedrosa, F. BaróMarine, S. Manrique, J. Casaldàliga-Ferrer, P. Tornos, L. Cabero, D. Garcia-Dorado, Cardiac complications during pregnancy are better predicted with the modified WHO risk score, Int. J. Cardiol. 195 (2015) 149-154.

[12] C.-W. Lu, J.-C. Shih, S.-Y. Chen, H.-H. Chiu, J.-K. Wang, C.-A. Chen, S.-N. Chiu, M.-T. Lin, C.-N. Lee, M.-H. Wu, Comparison of 3 risk estimation methods for predicting cardiac outcomes in pregnant women with congenital heart disease, Circulation journal : official journal of the Japanese Circulation Society. 79 (2015) 1609-1617.

[13] A. Balci, K.M. Sollie-Szarynska, A.G.L. van Der Bijl, T.P.E. Ruys, B.J.M. Mulder, J.W. Roos-Hesselink, A.P.J. van Dijk, E.M.C.J. Wajon, H.W. Vliegen, W. Drenthen, H.L Hillege, J.G. Aarnoudse, D.J. van Veldhuisen, P.G. Pieper, Prospective validation and assessment of cardiovascular and offspring risk models for pregnant women with congenital heart disease, Heart. 100 (2014) 1373.

[14] Y.Y. Kim, L.A. Goldberg, K. Awh, T. Bhamare, D. Drajpuch, A. Hirshberg, S.L. Partington, R. Rogers, E. Ruckdeschel, L. Tobin, M. Venuti, L.D. Levine, Accuracy of risk prediction scores in pregnant women with congenital heart disease, Congenit. Heart Dis. 14 (2019) 470-478.

[15] W.P. Khairy, M.D. Ouyang, E.S. Fernandes, J.A. Lee-Parritz, J.K. Economy, J.M. Landzberg, Pregnancy outcomes in women with congenital heart disease, Circulation. 113 (2006) 517-524.

[16] Y.B. Song, S.W. Park, J.H. Kim, D.-H. Shin, S.W. Cho, J.-O. Choi, S.-C. Lee, J.R. Moon, J. Huh, I.S. Kang, H.J. Lee, Outcomes of pregnancy in women with congenital heart disease: a single center experience in Korea, J. Korean Med. Sci. 23 (2008) 808-813.

[17] J.W. Roos-Hesselink, T.P.E. Ruys, J.I. Stein, U. Thilén, G.D. Webb, K. Niwa, H. Kaemmerer, H. Baumgartner, W. Budts, A.P. Maggioni, L. Tavazzi, N. Taha, M.R. Johnson, R. Hall, Outcome of pregnancy in patients with structural or ischaemic heart disease: results of a registry of the European Society of Cardiology, Eur. Heart J. 34 (2013) 657-665.

[18] E. Furenäs, P. Eriksson, U.-B. Wennerholm, M. Dellborg, Effect of maternal age and cardiac disease severity on outcome of pregnancy in women with congenital heart disease, Int. J. Cardiol. 243 (2017) 197-203.

[19] A.A.D. Ford, B. Wylie, D. Gersony, M.S. Rosenbaum, L. Simpson, C. Waksmonski, Maternal congenital cardiac disease - outcomes of pregnancy in a single tertiary care center, Obstet. Gynecol. 111 (2008) 42S-43S.

[20] J. Roos-Hesselink, L. Baris, M. Johnson, J. De Backer, C. Otto, A. Marelli, G. Jondeau, W. Budts, J. Grewal, K. Sliwa, W. Parsonage, A.P. Maggioni, I. van Hagen, A. Vahanian, L. Tavazzi, U. Elkayam, E. Boersma, R. Hall, Pregnancy outcomes in women with cardiovascular disease: evolving trends over 10 years in the ESC registry of pregnancy and cardiac disease (ROPAC), Eur. Heart J. 40 (2019) 3848-3855.

[21] O. Fu, J. Lin, Predictive accuracy of three clinical risk assessment systems for cardiac complications among Chinese pregnant women with congenital heart disease, Int. J. Gynecol. Obstet. 134 (2016) 140-144.

[22] I.M. Van Hagen, E. Boersma, M.R. Johnson, S.A. Thorne, W.A. Parsonage, P. Escribano Subías, A. Leśniak-Sobelga, O. Irtyuga, K.A. Sorour, N. Taha, A.P. Maggioni, R. Hall, J.W. Roos-Hesselink, Global cardiac risk assessment in the registry of pregnancy and cardiac disease: results of a registry from the European Society of Cardiology, Eur. J. Heart Fail. 18 (2016) 523-533. 
[23] Q. Fu, X.J. Wang, B.S. Wang, J.H. Lin, Cardiac risk prediction model for pregnant women with structural heart disease in eastern China, Int. J. Gynecol. Obstet. 145 (2019) 324-330.

[24] T.P.E. Ruys, J.W. Roos-Hesselink, R. Hall, M.T. Subirana-Domènech, J. Grando-Ting, M. Estensen, R. Crepaz, V. Fesslova, M. Gurvitz, J. De Backer, M.R. Johnson, P.G. Pieper, Heart failure in pregnant women with cardiac disease: data from the ROPAC, Heart. 100 (2014) 231.

[25] K. Sliwa, I.M. Van Hagen, W. Budts, L. Swan, G. Sinagra, M. Caruana, M.V. Blanco, L.J. Wagenaar, M.R. Johnson, G. Webb, R. Hall, J.W. Roos-Hesselink, Pulmonary hypertension and pregnancy outcomes: data from the registry of pregnancy and cardiac disease (ROPAC) of the European Society of Cardiology, Eur. J. Heart Fail. 18 (2016) 1119-1128.

[26] M. Ladouceur, L. Benoit, J. Radojevic, A. Basquin, C. Dauphin, S. Hascoet, P. Moceri, C. Bredy, L. Iserin, M. Gouton, J. Nizard, Pregnancy outcomes in patients with pulmonary arterial hypertension associated with congenital heart disease, Heart. 103 (2017). 